\title{
Platelet Interaction with Innate Immune Cells
}

\author{
Julia Barbara Kral Waltraud Cornelia Schrottmaier Manuel Salzmann Alice Assinger
}

Centre of Physiology and Pharmacology, Medical University of Vienna, Vienna, Austria

\section{Keywords}

Platelets · Platelet-leukocyte aggregates · P-selectin · Inflammation - Infection - Cardiovascular disease

\section{Summary}

Beyond their traditional role in haemostasis and thrombosis, platelets are increasingly recognised as immune modulatory cells. Activated platelets and platelet-derived microparticles can bind to leukocytes, which stimulates mutual activation and results in rapid, local release of platelet-derived cytokines. Thereby platelets modulate leukocyte effector functions and contribute to inflammatory and immune responses to injury or infection. Platelets enhance leukocyte extravasation, differentiation and cytokine release. Platelet-neutrophil interactions boost oxidative burst, neutrophil extracellular trap formation and phagocytosis and play an important role in host defence. Platelet interactions with monocytes propagate their differentiation into macrophages, modulate cytokine release and attenuate macrophage functions. Depending on the underlying pathology, platelets can enhance or diminish leukocyte cytokine production, indicating that platelet-leukocyte interactions represent a fine balanced system to restrict excessive inflammation during infection. In atherosclerosis, platelet interaction with neutrophils, monocytes and dendritic cells accelerates key steps of atherogenesis by promoting leukocyte extravasation and foam cell formation. Platelet-leukocyte interactions at sites of atherosclerotic lesions destabilise atherosclerotic plaques and promote plaque rupture. Leukocytes in turn also modulate platelet function and production, which either results in enhanced platelet destruction or increased platelet production. This review aims to summarise the key effects of platelet-leukocyte interactions in inflammation, infection and atherosclerosis.

(C) 2016 S. Karger GmbH, Freiburg

\section{Platelets and Innate Immune Cells during Injury}

Platelets are key players in haemostasis and prevent excessive bleeding upon injury. In response to vessel damage, platelets adhere and get activated at sites of injury, leading to recruitment of further platelets and thrombus formation. As injury represents a risk for infection, platelets recruit and activate leukocytes via direct cell-cell contacts and indirectly via cytokines and platelet-derived microvesicles. Activated platelets directly interact with leukocytes via $\mathrm{P}$-selectin $(\mathrm{CD} 62 \mathrm{P})$ interaction with $\mathrm{P}$-selectin glycoprotein ligand 1 (PSGL-1). This initial binding is enhanced by interaction of various other receptors, depending on the leukocyte subtype, leading to mutual activation and local cytokine release (reviewed in [1]), which modulates immune responses.

Upon activation platelets release a variety of a-granule-derived cytokines, chemokines and growth factors [2]. The mechanism of packaging inflammatory cargo into $\alpha$-granules, however, is incompletely understood [3]. Cytokines can be packaged into granules during megakaryopoiesis [4] either via biosynthesis in the megakaryocyte (e.g. platelet factor 4/CXCL4) or via endocytosis from the microenvironment (e.g. albumin) in the bone marrow [3]. Despite lacking a nucleus, platelets can splice and de novo synthesise proteins from megakaryocyte-derived (pre)mRNA as shown for IL-1 $\beta$ and IL-18 $[5,6]$. Via their open canalicular system platelets also take up factors from the circulation. Further platelets can fuse with microvesicles, which leads to intercellular exchanges of chemotactic receptors such as $\mathrm{C}-\mathrm{C}$ chemokine receptor type 5 (CCR5) and chemokine (C-X-C motif) receptor 4 (CXCR4) [7, 8]. Platelet cytokine levels have been demonstrated to be elevated in cancer patients $[9,10]$, indicating either an active uptake of these factors by platelets or disease-related changes in megakaryopoiesis. This suggests that underlying pathologies might influence not only platelet reactivity but also their potential to modulate immune responses. 
Fig. 1. Effects of platelets on innate immune cell functions during inflammation and infection.

Platelets promote monocyte and neutrophil extravasation via direct interaction and various chemokines. They further enhance leukocyte transmigration by endothelial cell activation via serotonin (5-HT) release. Platelets augment neutrophil effector functions by promoting phagocytosis and NETosis. Activated platelets further enhance oxidative burst and release of various inflammatory cytokines and enzymes of monocytes and neutrophils. Platelets direct monocytes towards a pro-inflammatory phe-

notype by inducing the expression of CD16 and CD86. However, platelets are also capable of dampening inflammatory responses by triggering IL-10 and downregulating IL-6 and TNF- $\alpha$ release by monocytes. Further, neutrophils can scavenge platelet mediated CCL3 and CCL5 and platelet-neutrophil aggregates generate Lipoxin $\mathrm{A} 4\left(\mathrm{LXA}_{4}\right)$ thereby eliciting anti-inflammatory responses.

5-HT = serotonin; CCL3 = chemokine (C-C motif) ligand 3; CD16 = cluster of differentiation 16; CXCL2 = chemokine (C-X-C motif) ligand 2; LXA $_{4}=$ Lipoxin A4; MCP-1 = monocyte chemoattractant protein $1 ; \mathrm{MIP}-1 \beta=$ macrophage inflammatory protein $1 \beta ; \mathrm{MMP} 9=$ matrix metalloproteinase- $9 ; \mathrm{MPO}=$ myeloperoxi dase; $R O S=$ reactive oxygen species.

\section{Platelet Interactions with Innate Immune Cells in Inflammation and Infection}

Apart from vessel damage, a variety of pathogens as well as inflammation triggers the activation of platelets. While certain viruses and bacteria exploit platelet interactions to gain virulence advantages, platelets mediate anti-microbial effects, which are either mediated via direct interaction with pathogens, or indirectly, by orchestrating leukocyte functions. Thus, platelets are important immune modulators during inflammation and infection. An overview of the effects of platelets during inflammation and infection is depicted in figure 1 and table 1.

Anti-platelet agents not only affect platelet aggregation and thrombosis, but also target immune modulatory effects of platelets. Aspirin and novel $\mathrm{P} 2 \mathrm{Y}_{12}$ receptor antagonists such as clopidogrel, prasugrel and ticagrelor reduce interaction of platelets with leukocytes and attenuate leukocyte recruitment and effector functions. Thereby, anti-platelet medication modulates a wide range of pathologic conditions (reviewed in $[1,11]$ ).

\section{Leukocyte Extravasation}

Platelets support leukocyte extravasation and tissue infiltration at sites of inflammation. Platelets adhere to the inflamed endothelium and mediate leukocyte rolling via glycoprotein $\mathrm{Ib}$ (GPIb) [12] and GPIIb/IIIa [13, 14]. Platelets enhance neutrophil rolling and firm adhesion via CD62P and chemokine CXCR2 [15-17].

Endothelial transmigration of neutrophils is elicited by binding of PSGL-1 [18] or CD11b/CD18 (MAC-1) to platelet CD62P [15], and is further enhanced by binding of CD40 to plateletderived soluble CD40 ligand (sCD40L) [19]. Binding of activated platelets to adhering neutrophils results in polarised receptor organisation, which represents a prerequisite for intravascular migration [20].

Activated neutrophils release a number of chemokines, which attract monocytes. Activated platelets further facilitate this process. Platelets directly interact with monocytes, leading to enhanced expression of CD40, PSGL-1, CD11b and CCR2 on the monocyte surface $[21,22]$. This, in turn, enhances platelet-monocyte aggregate formation and recruitment of further monocytes to the endothelium [21, 23-25]. The initial interaction between platelets and monocytes is mediated by CD62P-PSGL-1 binding [1], which is further stabilised by CD40L-MAC-1, GPVI-CD147 or via interaction of intercellular adhesion molecule 1 (ICAM-1) with plateletbound fibrinogen $[1,25]$. In addition to direct platelet-monocyte interactions, platelet-derived chemokines influence endothelial adhesion of monocytes. CXCL4, chemokine (C-C motif) ligand 5 (CCL5) and platelet-derived macrophage migration inhibiting factor (MIF) promote monocyte arrest on activated endothelial cells $[26,27]$. Platelet-derived MIF and stromal cell-derived growth fac- 


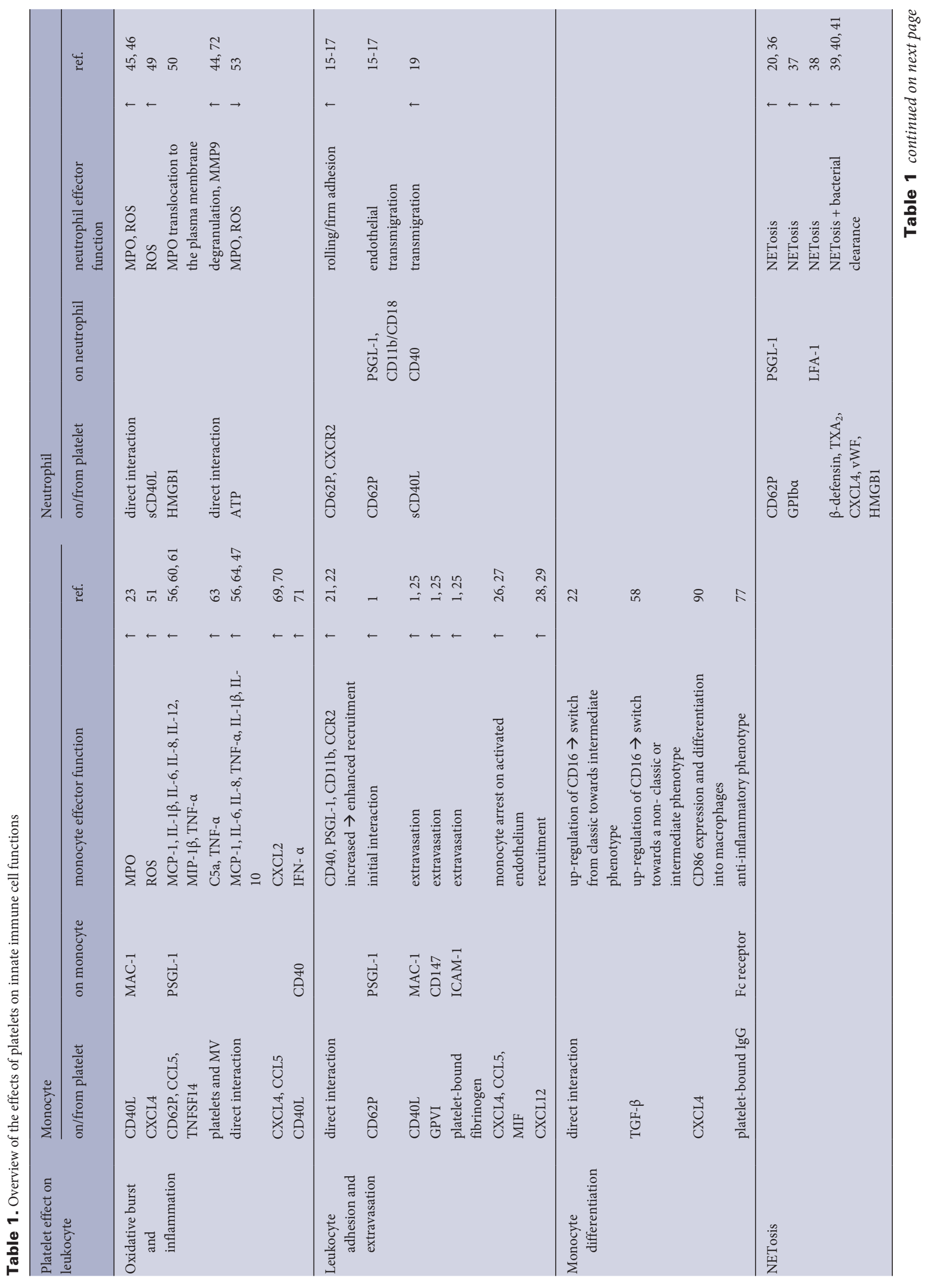




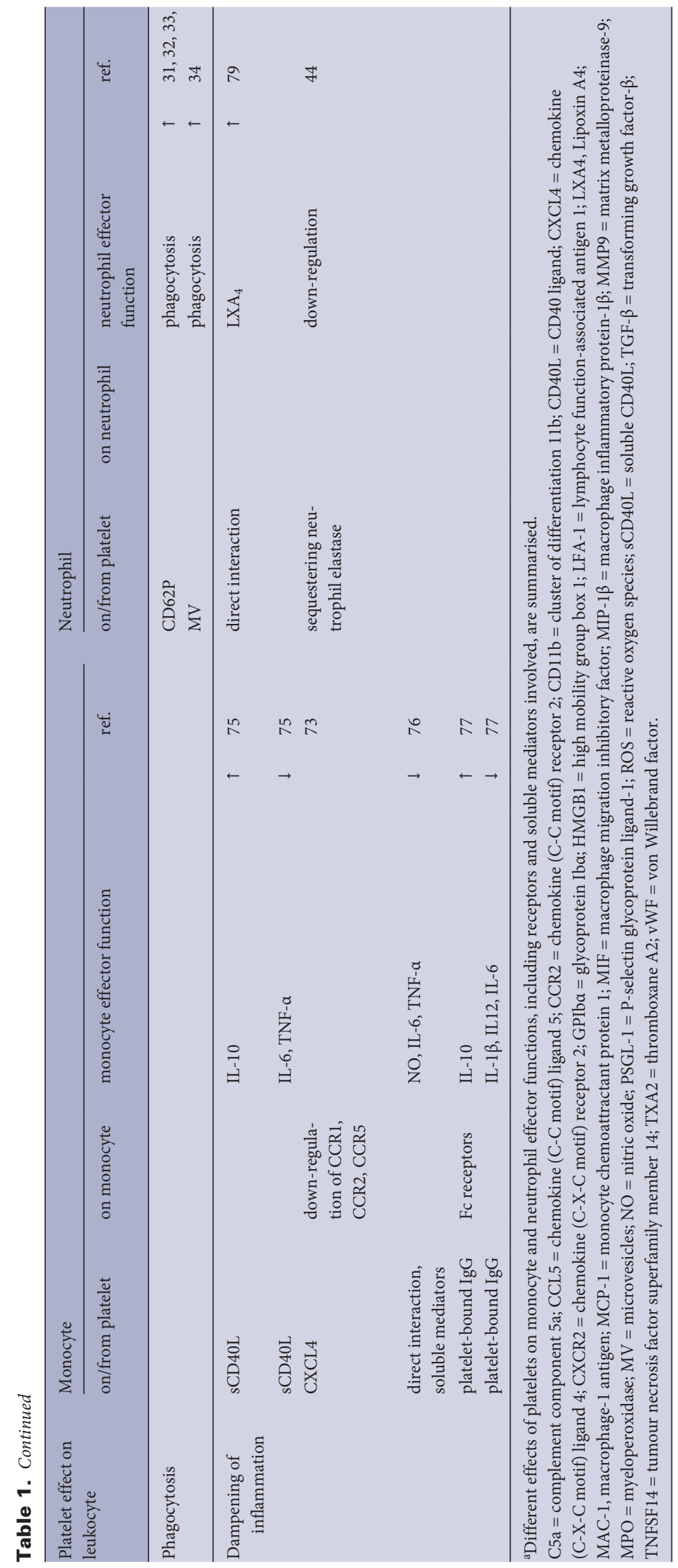


tor 1 (SDF-1/CXCL12) further increase monocyte recruitment via chemotaxis $[28,29]$.

Platelets also indirectly promote leukocyte migration via activation of endothelial cells. Platelet-derived serotonin, for example, induces secretion of endothelial Weibel-Palade bodies, leading to CD62P expression and release of IL-8, which triggers neutrophil rolling, adhesion and extravasation [30].

\section{Phagocytosis, Neutrophil Extracellular Trap Formation and \\ Bacterial Clearance}

Platelets and platelet-derived microvesicles can directly interact with neutrophils and enhance phagocytosis of various bacteria, including Aggregatibacter actinomycetemcomitans, Porphyromonas gingivalis, Neisseria meningitides and Streptococcus pyogenes [3134], thereby contributing to bacterial clearance.

Platelets are further involved in neutrophil extracellular trap (NET) formation, an apoptotic process, leading to release of neutrophil DNA, which ensnares bacteria. Toll-like receptor 4 (TLR4)-activated platelets bind to neutrophils, sticking to the endothelium, and initiate NET formation [35]. Platelets mediate NETosis either via CD62P-PSGL-1 interactions [20,36], platelet GPIba [37] or neutrophil lymphocyte-function-associated-antigen-1 (LFA-1) [38]. Additionally, platelet release products, like $\beta$-defensin [39], thromboxane $\mathrm{A}_{2}\left(\mathrm{TXA}_{2}\right)$, CXCL4, von Willebrand factor (vWF) [40] and high-mobility group box 1 protein (HMGB1) [41], trigger NET formation and increase bacterial clearance.

However, certain bacteria have overcome platelet-mediated host defence mechanisms. S. pyogenes, for example, induces large, fibrinogen-associated platelet-neutrophil complexes, which reduce neutrophil chemotaxis and phagocytosis, thus supporting bacterial survival [33]. Staphylococcus aureus a-toxin binds to platelet Adisintegrin-and-metalloproteinase-domain-containing-protein-10 (ADAM10) leading to proteolysis of the collagen receptor GPVI. This impairs collagen-induced platelet aggregation and endothelial repair, but also induces platelet degranulation and IL- $1 \beta$ production by leukocytes. Thereby, $S$. aureus $\alpha$-toxin exacerbates bacterial dissemination and accelerates pro-inflammatory responses, which lead to tissue damage and aggravate sepsis [42].

\section{Oxidative Burst}

Platelets modulate leukocyte oxidative burst by modulating the release of reactive oxygen species (ROS) and myeloperoxidase (MPO).

Platelets enhance MPO levels and oxidative stress in experimental models of acute colitis and immunecomplex-mediated inflammation $[43,44]$. Moreover, direct interaction of platelets and neutrophils promotes MPO formation in murine models of pancreatitis [45] and lipopolysaccharide(LPS)-induced acute lung injury [46]. Viral and bacterial infections are associated with increased levels of circulating platelet-leukocyte aggregates [47], which could enhance oxidative burst also during infections [48]. Platelet-derived soluble mediators are also involved in neutrophil oxidative burst formation. Platelet sCD40L stimulates neutrophils to pro- duce ROS [49], and platelet-derived HMGB1 triggers the translocation of MPO to the cell membrane [50].

Platelets further facilitate endogenous oxidative burst generation of monocytes to boost the destruction of phagocytosed pathogens. Platelet-induced ROS production in monocytes is modulated by direct interaction as well as secreted factors. Preventing direct platelet-monocyte interaction by blocking CD40L-MAC-1 interaction reduces the release of MPO from mouse monocytes [23]. Moreover, CXCL4 stimulation of monocytes enhances the phagocytic ability and triggers a respiratory burst [51] via activation of phosphoinositol-3-kinase, Syk and p38 [52], indicating that direct cell-cell interactions are not absolutely required for ROS induction.

However, platelets are also capable of down-regulating neutrophil ROS generation and MPO release via release of ATP from their dense granules [53], while in some pathologies platelets have no effect on MPO release at all [44].

\section{Monocyte Differentiation}

Platelets regulate monocyte functions by modulating their activation, polarisation and differentiation.

In humans, circulating monocytes can be classified in three subgroups, with distinct functions and phenotypes based on their CD14 and CD16 expression. Classical monocytes (CD14++, CD16-) are highly phagocytic cells and produce ROS, whereas the non-classical monocytes (CD14+, CD16++) patrol the endothelium and are involved in autoimmune diseases. The role of intermediate monocytes (CD14++, CD16+) is still controversial as they are associated with inflammatory diseases and release of IL- $1 \beta$ and TNF- $\alpha$, but also with production of IL-10 [54, 55]. Platelets preferentially bind to CD16+ monocytes and may also induce a phenotypical switch of classical monocytes towards CD16+ subsets [22]. The underlying mechanism of platelet-mediated modifications of monocyte phenotypes involves activation of the nuclear factor 'kappa-light-chain-enhancer' of activated B cells (NF- $\kappa \mathrm{B}$ ) pathway and signal transduction via phosphorylation of Lyn kinase [56, 57].

Activated platelets release tumour-derived growth factor $\beta$ (TGF- $\beta$ ) which also leads to up-regulation of CD16 on monocytes [58] and thus induces a switch towards intermediate and/or nonclassical monocytes. In vitro, platelet-derived TGF- $\beta$ promotes an inflammatory monocyte response by inducing cyclooxygenase 2 de novo synthesis via activation of the p38 MAPK pathway [59].

\section{Pro-Inflammatory Cytokine Expression}

Both direct and indirect platelet-derived signals drive leukocyte expression of pro-inflammatory cytokines. CD62P-PSGL-1 binding as well as platelet release of CCL5 and tumour necrosis factor superfamily member 14 (TNFSF14) induce monocyte expression of monocyte chemotactic protein 1 (MCP-1), TNF- $\alpha$, IL-1 $\beta$, IL-6, IL-8, IL-12 and macrophage inflammatory protein $1 \beta$ (MIP-1 $\beta$ ) in vitro $[56,60,61]$.

Platelet-induced intracellular signalling in monocytes or macrophages is highly complex and still incompletely understood. Coincubation with activated platelets and platelet-derived microvesicles enhances monocyte activation by inducing AKT signalling and 
intracellular calcium flux [62] and leads to complement factor C5a and TNF- $\alpha$ release [63].

Platelet-monocyte interactions further activate the monocyte $\mathrm{NF \kappa B}$ pathway to promote release of pro-inflammatory MCP-1, IL-8, TNF- $\alpha$ and IL-6 upon co-incubation in vitro $[56,64]$. Platelet CXCL4 induces extracellular signal kinase 1 and 2 (ERK1/2) phosphorylation, which mediates survival and differentiation, and Janus kinase (JNK) signalling, which leads to production and release of cytokines and chemokines [52].

The effect of platelets on monocytic release of pro-inflammatory molecules seems to depend on the type of pathogen, as platelets differentially affect TLR4- and TLR2-mediated inflammation in vitro [65]. Platelets reduce the expression of monocyte IL-10 upon stimulation with either TLR4 or TLR2 ligands. However, platelet TLR4 stimulation enhances IL- $1 \beta$, IL- 6 and TNF- $\alpha$ expression by isolated monocytes, whereas platelet stimulation via TLR2 reduces monocyte expression of these cytokines [65]. In line with this observation, TLR2 agonist lipoteichoic acid from S. aureus reduces platelet degranulation and platelet-monocyte aggregate formation [66]. The immune modulatory potential of platelets is therefore dependent on the underlying pathological conditions, as platelets from patients with dengue virus infection stimulate monocytes to produce MCP-1, IL-1 $\beta$, IL-8 and IL-10, while co-incubation of platelets and monocytes from healthy donors results only in increased MCP-1 release [47].

Platelets also confer pro-inflammatory effects on monocytes in vivo. Platelet inhibition reduces platelet-monocyte interaction and plasma levels of TNF- $\alpha$ during LPS-induced endotoxaemia in humans [67] and mice [68]. Platelet-derived CXCL4 and CCL5 are critical mediators of septic lung damage secondary to polymicrobial sepsis in a caecal ligation puncture (CLP) model as they trigger CXCL2 release of resident alveolar macrophages, thereby promoting neutrophil infiltration and tissue damage $[69,70]$.

Platelets further enhance IFN- $\alpha$ secretion of immune complexstimulated plasmacytoid dendritic cells via CD40L-CD40 interaction [71]. Platelets also enhance neutrophil activation and degranulation, leading to an increase in matrix metalloproteinase 9 (MMP9) release $[44,72]$. Thereby, platelets facilitate degradation of basement membranes by neutrophils.

During acute colitis platelet depletion is accompanied with decreased levels of CXCL2, CXCL5 and IL-6, indicating that platelets further influence inflammatory responses by acting on tissue macrophages or epithelial cells [43].

\section{Anti-Inflammatory Effects}

However, platelet function appears more multifaceted, pointing towards a finely balanced system with negative feedback mechanisms, to locally restrict inflammation. CXCL4 not only acts as an inflammatory mediator but also down-regulates the chemotactic receptors CCR1, CCR2 and CCR5 on isolated human monocytes, thereby interfering with monocyte migration [73]. Platelet-derived chrondroitin sulfate A blocks CCL5 binding to the endothelium, thereby suppressing firm monocyte adhesion in an in vitro flow model [74]. Furthermore, platelet-derived MIF has paracrine ef- fects on platelets, by reducing ADP-induced intracellular calcium flux, thereby potentially interfering with secondary platelet activation [27]. Secretion of sCD40L also elicits anti-inflammatory effects on monocytes by increasing IL-10 expression while concomitantly down-regulating TNF- $\alpha$ and IL-6 following in vitro stimulation of human monocytes [75]. In line with this, co-incubation with murine platelets reduces the production and release of inflammatory nitric oxide, TNF- $\alpha$ and IL- 6 of bone marrow-derived macrophages in vitro, indicating that platelets and their release products may attenuate inflammation during endotoxaemia [76]. Direct interaction of platelet-bound immunoglobulin $\mathrm{G}$ with monocytic $F c$ receptors drives monocytes towards an anti-inflammatory phenotype, reducing the levels of released inflammatory IL- $1 \beta$, IL-12 and IL- 6 while at the same time elevating IL-10 production in vitro and in an LPS-induced mouse peritonitis model [77]. In vivo data supports the dampening effect of platelets during infection, as GPIba-IX-deficient mice show enhanced inflammatory cytokines and chemokines in a CLP sepsis model [78]. The anti-inflammatory modulation of monocyte function may prevent uncontrolled cytotoxic responses during infections.

Also platelet interactions with neutrophils can lead to anti-inflammatory effects as platelet-neutrophil aggregate formation fosters generation of lipoxin A4, which down-regulates neutrophil adhesion and extravasation [79].

Activated platelets stimulate survival of neutrophils by the release of TGF- $\beta$ [80]. Apoptotic neutrophils express CCR5, which scavenges platelet-derived CCL3 and CCL5 [81], leading to downregulation of inflammatory responses.

Moreover, platelets are capable of preventing neutrophil-induced tissue damage by sequestering neutrophil elastase [44]. Platelet-dendritic cell interactions can also diminish dendritic cell activation via scavenging heat shock protein gp96, which acts as a dendritic cell activator [82].

Considering the opposing immune modulatory effects of platelets, their role in inflammation and infection is far more complex than previously thought. Depending on the underlying pathology, site of inflammation and experimental model employed, platelets exert either pro- or anti-inflammatory effects. The underlying mechanism, which drives platelets towards an immune enhancer or results in immune dampening effects, is currently incompletely understood. Further investigations to unveil the modality of the dual role of platelets in an inflammatory setting will be eagerly anticipated.

\section{Atherosclerosis}

Platelet-leukocyte interactions modulate initiation, development and progression of atherosclerosis (summarised in fig. 2).

Atherosclerosis is associated with increased platelet activation and enhanced release of platelet-derived pro-inflammatory cytokines like IL-1 $\beta$, sCD40L, CXCL4 and CCL5 [83], which promote activation of the endothelium. Activated platelets transiently adhere to endothelial cells and deposit CXCL4 and CCL5 [83], which en- 
Fig. 2. Effect of platelets on innate immune cell functions during atherogenesis (gray rectangle) and plaque rupture (white rectangle). Platelets and plateletderived chemokines promote monocyte, neutrophil and dendritic cell adhesion to inflamed endothelium and facilitate their extravasation Platelet CXCL4 further enhances survival of monocytes and neutrophils. Platelet CD40L induces ROS generation by neutrophils, which

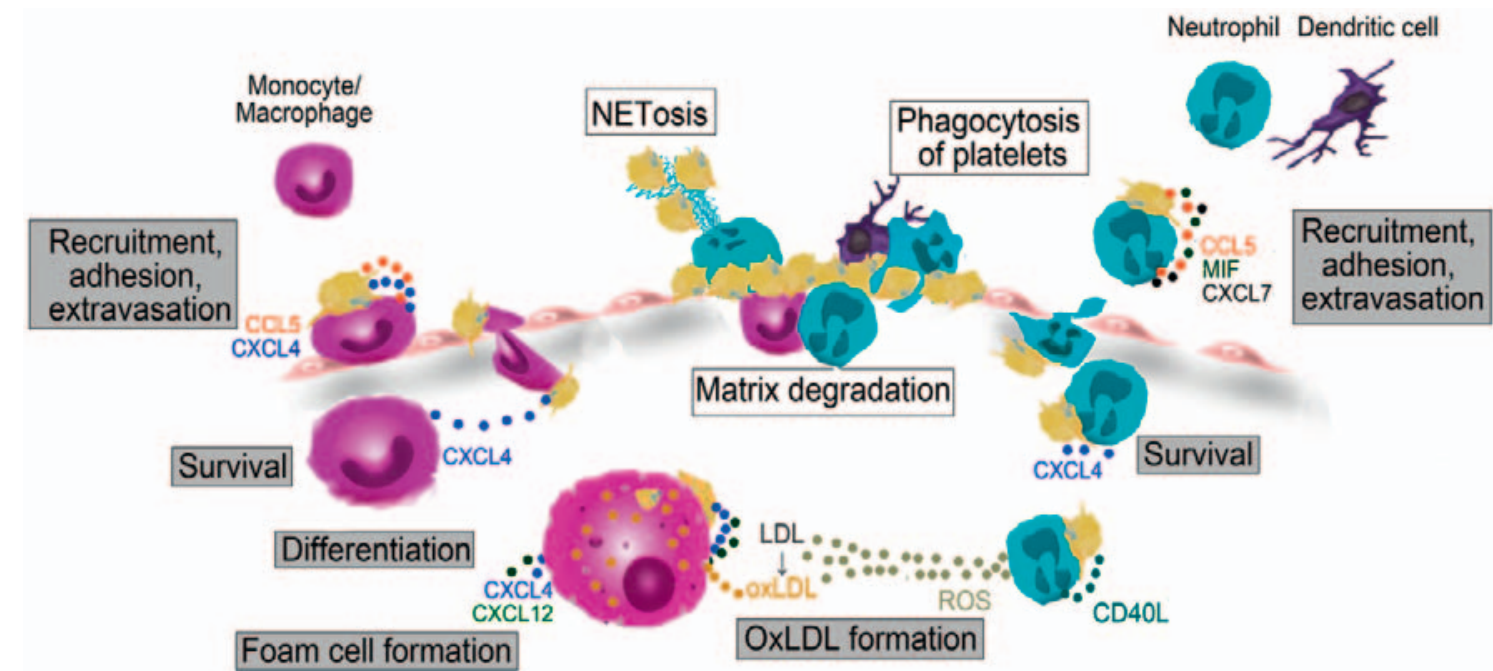

contributes to oxidation of LDL. Platelets trigger monocyte differentiation and macrophage polarization into pro-atherogenic M4 macrophages. Via CXCL4 and CXCL12 platelets enhance oxLDL uptake by monocytes and macrophages, leading to foam cell formation. Platelets promote the release of proteolytic enzymes by neutrophils and monocytes, which leads to extracellular matrix degradation and plaque destabilization. Neutrophils and dendritic cells phagocytose activated platelets, which modulates leukocyte functions. Platelet-mediated NETs contribute to additional platelet trapping and thrombus formation. CCL5 = Chemokine (C-C motif) ligand 5; CD40L = cluster of differentiation 40 ligand; CXCL4 = chemokine (C-X-C motif) ligand 4; LDL = low density lipoprotein; MIF = macrophage migration inhibitory factor; oxLDL = oxidised LDL.

hance monocyte adhesion and tissue infiltration [22]. The proinflammatory microenvironment at sites of endothelial dysfunction further promotes platelet adhesion and activation [84]. This enhances the release of platelet-derived chemokines like CCL5, MIF and CXCL7, which leads to neutrophil recruitment $[85,86]$. The pro-inflammatory, pro-oxidative state at atherosclerotic sites leads to modification of low-density lipoproteins (LDL). LDL oxidation is furthered by platelet release of $\mathrm{SCD} 40 \mathrm{~L}$, which induces ROS production by neutrophils [49]. Thereby, platelets contribute to LDL oxidation and endothelial dysfunction [85]. Oxidised LDL, in turn, activates platelets, leading to platelet-neutrophil aggregate formation, which accelerates neutrophil activation and transmigration [87].

Platelet-mediated adhesion of monocytes and dendritic cells via direct cell-cell interactions at sites of atherosclerotic lesions $[83,84$, 88] promotes atherogenesis [83, 89].

Platelet-derived CXCL4 prevents apoptosis of neutrophils [86] and monocytes, and induces monocyte CD86 expression and differentiation into macrophages [90]. These CXCL4-induced macrophages have distinct properties from classical M1 and alternatively activated M2 macrophages and are thus defined as M4 polarized macrophages, which exert a pro-atherogenic phenotype (reviewed in [91]).

Platelets further accelerate lipid uptake and foam cell formation by enhancing cholesterol uptake by monocytes [92-94]. This process is mediated by CXCL4, CXCL12, platelet-derived growth factor (PDGF) and phagocytosis of lipid-laden platelets, which have taken up modified LDL [22, 28, 95, 96].

Platelet depletion reduces foam cell formation [22], and CXCL4 deficiency diminishes atherosclerotic lesion development and size [97], while mice with hyper-reactive platelets show increased atherosclerotic lesion formation [84].

\section{Plaque Rupture and Atherothrombosis}

The stability of an atherosclerotic plaque is determined by inflammatory cytokines and cells present at sites of lesions. Activated platelets at atherosclerotic lesions recruit neutrophils, which secrete proteolytic enzymes like elastase, MMP8, MMP9, MPO or proteinase 3 , thereby decreasing plaque stability $[85,98]$. Activated platelets induce release of tissue factor-covered NETs by neutrophils at sites of plaque rupture, thus contributing to thrombus progression [85]. Lysophosphatidic acid within atherosclerotic plaques activates platelets in vitro, promoting platelet-monocyte aggregate formation, which may result in enhanced inflammatory and thrombotic stimulation in vivo [99]. Platelet-monocyte interactions further enhance matrix MMP9 production, and thereby contribute to plaque destabilisation $[100,101]$.

Immature myeloid dendritic cells interact with activated platelets only under low shear conditions found at sites of atherosclerotic lesions. Platelet-dendritic cell interaction damages plaque structure [102]. Neutrophils and dendritic cells can phagocytose activated platelets from preformed aggregates and thus may regulate inflammatory responses and atherothrombotic events [103, 104].

\section{Megakaryopoiesis}

Platelets are produced by megakaryocytes in the bone marrow. Megakaryocytes derive from haematopoietic stem cells, and their differentiation process is strictly regulated by a plethora of cytokines, including IL-1 $\alpha$, IL-1 $\beta$, IL-3, IL-6, IL-8, IL-9, IL-11, granulocyte colony-stimulating factor (G-CSF), granulocyte-macrophage 
Table 2. Effect of innate immune cells on megakaryopoiesis and effects of megakaryocytes and platelets on leukocyte production ${ }^{2}$

\begin{tabular}{|c|c|c|c|}
\hline & \multicolumn{2}{|c|}{ Leukocytes $\rightarrow$ megakaryopoiesis } & \multirow{2}{*}{$\begin{array}{l}\text { MKs/platelets } \rightarrow \\
\text { leukopoiesis }\end{array}$} \\
\hline & stimulatory & inhibitory & \\
\hline IL-1a & [113] & & \\
\hline IL- $1 \beta$ & {$[105,117]$} & & [105] \\
\hline IL-3 & & & [106] \\
\hline IL-6 & {$[112,117,118]$} & & [116] \\
\hline IL-8/KC & {$[118]$} & & [114] \\
\hline IL-9 & [119] & & \\
\hline IL-11 & {$[106]$} & & \\
\hline G-CSF & {$[114,117]$} & & \\
\hline GM-CSF & {$[106,108]$} & & [115] \\
\hline TGF- $\beta$ & & [109] & \\
\hline ROS & [111] & & \\
\hline Unique NK cell peptide & [109] & & \\
\hline
\end{tabular}

${ }^{\mathrm{a}}$ Macrophage and nuetrophil-derived interleukin-1 $\alpha$ (IL-1 $\alpha$ ) induces megakaryocyte rupture, which results in rapid production of large amounts of platelets. Monocytes, macrophages, neutrophils and NK cells release IL-1 $\beta$, IL-6, IL-8, IL-9, IL-11, granulocyte colony-stimulating factor (G-CSF), granulocytemacrophage colony-stimulating factor (GM-CSF) and reactive oxygen species (ROS), which stimulates haematopoietic stem cell proliferation and megakaryocyte maturation. IL-2 stimulated NK cells secrete a unique peptide that stimulates megakaryopoiesis independent of thrombopoietin (TPO). Transforming growth factor- $\beta$ (TGF- $\beta$ )-derived from NK cells can inhibit megakaryopoiesis. Megakaryocytes also influence leukocyte blood counts by enhancing neutrophil mobility and release into the circulation or via the release of IL-1 $\beta$, IL-3, IL-6, IL-8 and GM-CSF. colony-stimulating factor (GM-CSF) and thrombopoietin (TPO) [105-108].

A number of inflammatory states are associated with elevated platelet counts and increased blood TPO, which represents an important mediator of megakaryopoiesis and platelet production $[109,110]$. The effects of innate leukocytes on megakaryopoiesis and the effect of megakaryocytes on innate leukocyte counts are summarised in table 2 .

Via release of ROS, activated macrophages and neutrophils enhance haematopoietic stem cell commitment towards the megakaryocytic lineage and accelerate megakaryocyte maturation [111]. Activated leukocytes release GM-CSF, G-CSF, IL-1 $\alpha$, IL-1 $\beta$, IL-6, IL-8, IL-11 and a unique natural killer (NK) cell peptide, thereby promoting megakaryopoiesis [105, 106, 109, 111-113]. Many leukocyte-derived cytokines induce TPO expression as well as commitment, maturation and/or rupture of megakaryocytes. This leads to increased platelet counts during acute inflammatory stimuli. Leukocytes can also diminish platelet production via release of TGF- $\beta$, which is a potent inhibitor of megakaryopoiesis and megakaryocytotic endomitosis [109].
Megakaryocytes, in turn, influence neutrophil blood counts via IL-8 and macrophage inflammatory protein 2 (MIP-2) release, which promotes neutrophil migration. Stimulation of megakaryocytes induces the release of IL-8 and MIP-2, which bind to CXCR2 to initiate vessel migration and subsequent release of neutrophils into the circulation [114]. Megakaryocyte-derived IL-1 $\beta$, IL-3 and GM-CSF induce granulopoiesis [105, 115], and IL-6 treatment increases not only neutrophil and platelet counts but also monocytes and NK cell levels [116].

\section{Acknowledgement}

This study was supported by the Austrian Science Fund (FWF-P24978 and FWF-SFB-54) and by the funding agency of the Austrian National Bank (OeNB grant 15961).

\section{Disclosure Statement}

The authors declared no conflict of interest.

\section{References}

Schrottmaier WC, Kral JB, Badrnya S, Assinger A: Aspirin and P2Y12 inhibitors in platelet-mediated activation of neutrophils and monocytes. Thromb Haemost 2015;114:478-489.

2 McNicol A, Israels SJ: Beyond hemostasis: the role of platelets in inflammation, malignancy and infection. Cardiovasc Hematol Disord Drug Targets 2008;8:99_ 117.
Heijnen $\mathrm{H}$, van der Sluijs P: Platelet secretory behaviour: as diverse as the granules ... or not? J Thromb Haemost 2015;13:2141-2151.

4 Veljkovic DK, Cramer EM, Alimardani G, Fichelson S, Masse JM, Hayward CP: Studies of alpha-granule proteins in cultured human megakaryocytes. Thromb Haemost 2003;90:844-852
Lindemann S, Tolley ND, Dixon DA, McIntyre TM, Prescott SM, Zimmerman GA, Weyrich AS: Activated platelets mediate inflammatory signaling by regulated interleukin lbeta synthesis. J Cell Biol 2001;154:485-490.

6 Allam O, Samarani S, Marzouk R, Ahmad A: Human platelets produce and constitute the main source of il-18 in the circulation. J Immunol 2012;188 (Meeting Abstract Suppl):44.25. 
7 Mack M, Kleinschmidt A, Bruhl H, Klier C, Nelson PJ, Cihak J, Plachy J, Stangassinger M, Erfle V, Schlondorff D: Transfer of the chemokine receptor ccr5 between cells by membrane-derived microparticles: a mechanism for cellular human immunodeficiency virus 1 infection. Nat Med 2000;6:769-775.

8 Rozmyslowicz T, Majka M, Kijowski J, Murphy SL, Conover DO, Poncz M, Ratajczak J, Gaulton GN, Ratajczak MZ: Platelet- and megakaryocyte-derived microparticles transfer CXCR4 receptor to CXCR4null cells and make them susceptible to infection by X4-HIV. Aids 2003;17:33-42.

${ }_{9}$ Fu BH, Fu ZZ, Meng W, Gu T, Sun XD, Zhang Z: Platelet VEGF and serum TGF-betal levels predict chemotherapy response in non-small cell lung cancer patients. Tumour Biol 2015;36:6477-6483.

10 Peterson JE, Zurakowski D, Italiano JE Jr, Michel LV, Connors S, Oenick M, D'Amato RJ, Klement GL, Folkman J: VEGF, PF4 and PDGF are elevated in platelets of colorectal cancer patients. Angiogenesis 2012;15: 265-273.

11 Schror K, Huber K: Platelets, inflammation and antiinflammatory drugs in ACS and CAD. Thromb Haemost 2015;114:446-448.

12 Hillgruber C, Steingraber AK, Poppelmann B, Denis CV, Ware J, Vestweber D, Nieswandt B, Schneider SW, Goerge T: Blocking von Willebrand factor for treatment of cutaneous inflammation. J Invest Dermatol 2014;134:77-86.

13 Slaba I, Wang J, Kolaczkowska E, McDonald B, Lee WY, Kubes P: Imaging the dynamic platelet-neutrophil response in sterile liver injury and repair in mice. Hepatology 2015;62:1593-1605.

14 Weber C, Springer TA: Neutrophil accumulation on activated, surface-adherent platelets in flow is mediated by interaction of Mac-1 with fibrinogen bound to alphaiibbeta3 and stimulated by platelet-activating factor. J Clin Invest 1997;100:2085-2093.

- 15 Diacovo TG, Roth SJ, Buccola JM, Bainton DF, Springer TA: Neutrophil rolling, arrest, and transmigration across activated, surface-adherent platelets via sequential action of P-selectin and the beta 2-integrin CD11b/CD18. Blood 1996;88:146-157.

16 Kuligowski MP, Kitching AR, Hickey MJ: Leukocyte recruitment to the inflamed glomerulus: a critical role for platelet-derived p-selectin in the absence of rolling. J Immunol 2006;176:6991-6999.

17 Stone PC, Nash GB: Conditions under which immobilized platelets activate as well as capture flowing neutrophils. Br J Haematol 1999; 105:514-522.

18 Lam FW, Burns AR, Smith CW, Rumbaut RE: Platelets enhance neutrophil transendothelial migration via $\mathrm{P}$ selectin glycoprotein ligand-1. Am J Physiol Heart Circ Physiol 2011;300:H468-475.

19 Rahman M, Roller J, Zhang S, Syk I, Menger MD, Jeppsson B, Thorlacius H: Metalloproteinases regulate CD40l shedding from platelets and pulmonary recruitment of neutrophils in abdominal sepsis. Inflamm Res 2012;61:571-579.

-20 Sreeramkumar V, Adrover JM, Ballesteros I, Cuartero MI, Rossaint J, Bilbao I, Nacher M, Pitaval C, Radovanovic I, Fukui Y, McEver RP, Filippi MD, Lizasoain I, Ruiz-Cabello J, Zarbock A, Moro MA, Hidalgo A: Neutrophils scan for activated platelets to initiate inflammation. Science 2014;346:1234-1238.

21 Singh MV, Davidson DC, Jackson JW, Singh VB, Silva J, Ramirez SH, Maggirwar SB: Characterization of platelet-monocyte complexes in HIV-1-infected individuals: possible role in HIV-associated neuroinflammation. J Immunol 2014;192:4674-4684.

22 Badrnya S, Schrottmaier WC, Kral JB, Yaiw KC, Volf I, Schabbauer G, Soderberg-Naucler C, Assinger A: Platelets mediate oxidized low-density lipoprotein-induced monocyte extravasation and foam cell formation. Arterioscler Thromb Vasc Biol 2014;34:571-580.
3 Zirlik A, Maier C, Gerdes N, MacFarlane L, Soosairajah J, Bavendiek U, Ahrens I, Ernst S, Bassler N, Missiou A, Patko Z, Aikawa M, Schonbeck U, Bode C, Libby P, Peter K: CD40 ligand mediates inflammation independently of CD40 by interaction with Mac-1. Circulation 2007;115:1571-1580.

24 Schulz C, von Bruhl ML, Barocke V, Cullen P, Mayer K, Okrojek R, Steinhart A, Ahmad Z, Kremmer E, Nieswandt B, Frampton J, Massberg S, Schmidt R: EMMPRIN (CD147/basigin) mediates platelet-monocyte interactions in vivo and augments monocyte recruitment to the vascular wall. J Thromb Haemost 2011;9:1007-1019.

25 Armstrong PC, Kirkby NS, Chan MV, Finsterbusch M, Hogg N, Nourshargh S, Warner TD: Novel whole blood assay for phenotyping platelet reactivity in mice identifies ICAM-1 as a mediator of platelet-monocyte interaction. Blood 2015;126:e11-18.

26 von Hundelshausen P, Koenen RR, Sack M, Mause SF, Adriaens W, Proudfoot AE, Hackeng TM, Weber C: Heterophilic interactions of platelet factor 4 and RANTES promote monocyte arrest on endothelium. Blood 2005; 105:924-930.

27 Wirtz TH, Tillmann S, Strussmann T, Kraemer S, Heemskerk JW, Grottke O, Gawaz M, von Hundelshausen P, Bernhagen J: Platelet-derived MIF: a novel platelet chemokine with distinct recruitment properties. Atherosclerosis 2015;239:1-10.

28 Chatterjee M, von Ungern-Sternberg SN, Seizer P, Schlegel F, Buttcher M, Sindhu NA, Muller S, Mack A, Gawaz M: Platelet-derived CXCL12 regulates monocyte function, survival, differentiation into macrophages and foam cells through differential involvement of CXCR4-CXCR7. Cell Death Dis 2015;6:e1989.

29 Strussmann T, Tillmann S, Wirtz T, Bucala R, von Hundelshausen P, Bernhagen J: Platelets are a previously unrecognised source of MIF. Thromb Haemost 2013;110:1004-1013.

30 Duerschmied D, Suidan GL, Demers M, Herr N, Carbo C, Brill A, Cifuni SM, Mauler M, Cicko S, Bader M, Idzko M, Bode C, Wagner DD: Platelet serotonin promotes the recruitment of neutrophils to sites of acute inflammation in mice. Blood 2013;121:1008-1015.

31 Assinger A, Laky M, Schabbauer G, Hirschl AM, Buchberger E, Binder BR, Volf I: Efficient phagocytosis of periodontopathogens by neutrophils requires plasma factors, platelets and TLR2. J Thromb Haemost 2011;9: 799-809.

32 Peters MJ, Dixon G, Kotowicz KT, Hatch DJ, Heyderman RS, Klein NJ: Circulating platelet-neutrophil complexes represent a subpopulation of activated neutrophils primed for adhesion, phagocytosis and intracellular killing. Br J Haematol 1999;106:391-399.

33 Hurley SM, Kahn F, Nordenfelt P, Morgelin M, Sorensen OE, Shannon O: Platelet-dependent neutrophil function is dysregulated by $\mathrm{m}$ protein from Streptococcus pyogenes. Infect Immun 2015;83:3515-3525.

34 Jy W, Mao WW, Horstman L, Tao J, Ahn YS: Platelet microparticles bind, activate and aggregate neutrophils in vitro. Blood Cells Mol Dis 1995;21:217-231; discussion 231a.

35 Caudrillier A, Kessenbrock K, Gilliss BM, Nguyen JX, Marques MB, Monestier M, Toy P, Werb Z, Looney MR: Platelets induce neutrophil extracellular traps in transfusion-related acute lung injury. J Clin Invest 2012;122:2661-2671.

36 Etulain J, Martinod K, Wong SL, Cifuni SM, Schattner M, Wagner DD: P-selectin promotes neutrophil extracellular trap formation in mice. Blood 2015;126:242246.
37 von Bruhl ML, Stark K, Steinhart A, Chandraratne S, Konrad I, Lorenz M, Khandoga A, Tirniceriu A, Coletti R, Kollnberger M, Byrne RA, Laitinen I, Walch A, Brill A, Pfeiler S, Manukyan D, Braun S, Lange P, Riegger J, Ware J, Eckart A, Haidari S, Rudelius M, Schulz C, Echtler K, Brinkmann V, Schwaiger M, Preissner KT, Wagner DD, Mackman N, Engelmann B, Massberg S: Monocytes, neutrophils, and platelets cooperate to initiate and propagate venous thrombosis in mice in vivo. J Exp Med 2012;209:819-835.

38 McDonald B, Kubes P: Neutrophils and intravascular immunity in the liver during infection and sterile inflammation. Toxicol Pathol 2012;40:157-165.

39 Kraemer BF, Campbell RA, Schwertz H, Cody MJ, Franks Z, Tolley ND, Kahr WH, Lindemann S, Seizer P, Yost CC, Zimmerman GA, Weyrich AS: Novel antibacterial activities of beta-defensin 1 in human platelets: suppression of pathogen growth and signaling of neutrophil extracellular trap formation. PLoS Pathog 2011;7:e1002355

40 Carestia A, Kaufman T, Rivadeneyra L, Landoni VI, Pozner RG, Negrotto S, D'Atri LP, Gomez RM, Schattner M: Mediators and molecular pathways involved in the regulation of neutrophil extracellular trap formation mediated by activated platelets. J Leukoc Biol 2016;99:153-162

41 Maugeri N, Campana L, Gavina M, Covino C, De Metrio $\mathrm{M}$, Panciroli $\mathrm{C}$, Maiuri L, Maseri A, D’Angelo A, Bianchi ME, Rovere-Querini P, Manfredi AA: Activated platelets present high mobility group box 1 to neutrophils, inducing autophagy and promoting the extrusion of neutrophil extracellular traps. J Thromb Haemost 2014;12:2074-2088.

42 Powers ME, Becker RE, Sailer A, Turner JR, Bubeck Wardenburg J: Synergistic action of Staphylococcus aureus alpha-toxin on platelets and myeloid lineage cells contributes to lethal sepsis. Cell Host Microbe 2015;17: 775-787.

43 Yu C, Zhang S, Wang Y, Zhang S, Luo L, Thorlacius H: Platelet-derived CCL5 regulates CXC chemokine formation and neutrophil recruitment in acute experimental colitis. J Cell Physiol 2016;231:370-376.

44 Gros A, Syvannarath V, Lamrani L, Ollivier V, Loyau S, Goerge T, Nieswandt B, Jandrot-Perrus M, Ho-TinNoe B: Single platelets seal neutrophil-induced vascular breaches via GPVI during immune-complex-mediated inflammation in mice. Blood 2015;126:1017-1026.

45 Parimon T, Li Z, Bolz DD, McIndoo ER, Bayer CR, Stevens DL, Bryant AE: Staphylococcus aureus alphahemolysin promotes platelet-neutrophil aggregate formation. J Infect Dis 2013;208:761-770.

46 Ortiz-Munoz G, Mallavia B, Bins A, Headley M Krummel MF, Looney MR: Aspirin-triggered 15-epilipoxin A4 regulates neutrophil-platelet aggregation and attenuates acute lung injury in mice. Blood 2014; 124:2625-2634.

47 Hottz ED, Medeiros-de-Moraes IM, Vieira-de-Abreu A, de Assis EF, Vals-de-Souza R, Castro-Faria-Neto HC, Weyrich AS, Zimmerman GA, Bozza FA, Bozza PT: Platelet activation and apoptosis modulate monocyte inflammatory responses in dengue. J Immunol 2014;193:1864-1872.

48 Assinger A, Kral JB, Yaiw KC, Schrottmaier WC, Kurzejamska E, Wang Y, Mohammad AA, Religa P, Rahbar A, Schabbauer G, Butler LM, Soderberg-Naucler C: Human cytomegalovirus-platelet interaction triggers toll-like receptor 2-dependent proinflammatory and proangiogenic responses. Arterioscler Thromb Vasc Biol 2014;34:801-809.

49 Vanichakarn P, Blair P, Wu C, Freedman JE, Chakrabarti S: Neutrophil CD40 enhances platelet-mediated inflammation. Thromb Res 2008;122:346-358. 
50 Maugeri N, Rovere-Querini P, Baldini M, Baldissera E, Sabbadini MG, Bianchi ME, Manfredi AA: Oxidative stress elicits platelet/leukocyte inflammatory interactions via HMGB1: a candidate for microvessel injury in sytemic sclerosis. Antioxid Redox Signal 2014;20: 1060-1074.

51 Pervushina O, Scheuerer B, Reiling N, Behnke L, Schroder JM, Kasper B, Brandt E, Bulfone-Paus S, Petersen F: Platelet factor 4/CXCL4 induces phagocytosis and the generation of reactive oxygen metabolites in mononuclear phagocytes independently of GI protein activation or intracellular calcium transients. J Immunol 2004; 173:2060-2067.

52 Kasper B, Brandt E, Brandau S, Petersen F: Platelet factor 4 (CXC chemokine ligand 4) differentially regulates respiratory burst, survival, and cytokine expression of human monocytes by using distinct signaling pathways. J Immunol 2007; 179:2584-2591.

53 Lecut C, Faccinetto C, Delierneux C, van Oerle R, Spronk HM, Evans RJ, El Benna J, Bours V, Oury C: ATP-gated P2X1 ion channels protect against endotoxemia by dampening neutrophil activation. J Thromb Haemost 2012;10:453-465.

54 Yang J, Zhang L, Yu C, Yang XF, Wang H: Monocyte and macrophage differentiation: circulation inflammatory monocyte as biomarker for inflammatory diseases. Biomark Res 2014;2:1.

55 Idzkowska E, Eljaszewicz A, Miklasz P, Musial WJ, Tycinska AM, Moniuszko M: The role of different monocyte subsets in the pathogenesis of atherosclerosis and acute coronary syndromes. Scand J Immunol 2015;82. 163-173.

56 Weyrich AS, Elstad MR, McEver RP, McIntyre TM, Moore KL, Morrissey JH, Prescott SM, Zimmerman GA: Activated platelets signal chemokine synthesis by human monocytes. J Clin Invest 1996;97:1525-1534.

57 Christersson C, Johnell M, Siegbahn A: Tissue factor and IL8 production by P-selectin-dependent plateletmonocyte aggregates in whole blood involves phosphorylation of Lyn and is inhibited by IL10. J Thromb Haemost 2008;6:986-994.

58 Phillips JH, Chang CW, Lanier LL: Platelet-induced expression of $\mathrm{Fc}$ gamma RIII (CD16) on human monocytes. Eur J Immunol 1991;21:895-899.

59 Eligini S, Barbieri SS, Arenaz I, Tremoli E, Colli S: Paracrine up-regulation of monocyte cyclooxygenase- 2 by platelets: role of transforming growth factor-betal. Cardiovasc Res 2007;74:270-278.

60 Suzuki J, Hamada E, Shodai T, Kamoshida G, Kudo S, Itoh S, Koike J, Nagata K, Irimura T, Tsuji T: Cytokine secretion from human monocytes potentiated by $\mathrm{P}$ selectin-mediated cell adhesion. Int Arch Allergy Immunol 2013;160:152-160.

61 Otterdal K, Smith C, Oie E, Pedersen TM, Yndestad A, Stang E, Endresen K, Solum NO, Aukrust P, Damas JK: Platelet-derived light induces inflammatory responses in endothelial cells and monocytes. Blood 2006; 108:928-935.

62 Stephen J, Emerson B, Fox KA, Dransfield I: The uncoupling of monocyte-platelet interactions from the induction of proinflammatory signaling in monocytes. J Immunol 2013;191:5677-5683.

63 Vasina EM, Cauwenberghs S, Feijge MA, Heemskerk JW, Weber C, Koenen RR: Microparticles from apoptotic platelets promote resident macrophage differentiation. Cell Death Dis 2011;2:e211.

64 Rong MY, Wang $\mathrm{CH}$, Wu ZB, Zeng W, Zheng ZH, Han Q, Jia JF, Li XY, Zhu P: Platelets induce a proinflammatory phenotype in monocytes via the CD147 pathway in rheumatoid arthritis. Arthritis Res Ther 2014; 16:478.
65 Tunjungputri RN, van der Ven AJ, Riksen N, Rongen G, Tacke S, van den Berg TN, Fijnheer R, Gomes ME, Dinarello CA, van de Veerdonk FL, Gasem MH, Netea MG, Joosten LA, de Groot PG, de Mast Q: Differential effects of platelets and platelet inhibition by ticagrelor on TLR2- and TLR4-mediated inflammatory responses. Thromb Haemost 2015;113:1035-1045.

66 Wu BQ, Zhi MJ, Liu H, Huang J, Zhou YQ, Zhang TT: Inhibitory effects of lipoteichoic acid from Staphylococcus aureus on platelet function and platelet-monocyte aggregation. Inflamm Res 2011;60:775-782.

67 Thomas MR, Outteridge SN, Ajjan RA, Phoenix F, Sangha GK, Faulkner RE, Ecob R, Judge HM, Khan H, West LE, Dockrell DH, Sabroe I, Storey RF: Platelet P2Y12 inhibitors reduce systemic inflammation and its prothrombotic effects in an experimental human model. Arterioscler Thromb Vasc Biol 2015;35:2562-2570.

68 Totani L, Dell'Elba G, Martelli N, Di Santo A, Piccoli A, Amore C, Evangelista V: Prasugrel inhibits plateletleukocyte interaction and reduces inflammatory markers in a model of endotoxic shock in the mouse. Thromb Haemost 2012;107:1130-1140.

69 Hwaiz R, Rahman M, Syk I, Zhang E, Thorlacius H: Racl-dependent secretion of platelet-derived CCL5 regulates neutrophil recruitment via activation of alveolar macrophages in septic lung injury. J Leukoc Biol 2015; doi: 10.1189/jlb.4A1214-603R.

70 Hwaiz R, Rahman M, Zhang E, Thorlacius H: Platelet secretion of CXCL4 is Racl-dependent and regulates neutrophil infiltration and tissue damage in septic lung damage. Br J Pharmacol 2015;172:5347-5359.

71 Duffau P, Seneschal J, Nicco C, Richez C, Lazaro E, Douchet I, Bordes C, Viallard JF, Goulvestre C, Pellegrin JL, Weil B, Moreau JF, Batteux F, Blanco P: Platelet CD154 potentiates interferon-alpha secretion by plasmacytoid dendritic cells in systemic lupus erythematosus. Sci Translat Med 2010;2:47ra63.

72 Clark SR, Ma AC, Tavener SA, McDonald B, Goodarzi Z, Kelly MM, Patel KD, Chakrabarti S, McAvoy E, Sinclair GD, Keys EM, Allen-Vercoe E, Devinney R, Doig CJ, Green FH, Kubes P: Platelet TLR4 activates neutrophil extracellular traps to ensnare bacteria in septic blood. Nat Med 2007;13:463-469.

73 Schwartzkopff F, Petersen F, Grimm TA, Brandt E: Cxc chemokine ligand 4 (CXCL4) down-regulates CC chemokine receptor expression on human monocytes. Innate Immun 2012;18:124-139.

74 Mack M, Pfirstinger J, Weber C, Weber KS, Nelson PJ, Rupp T, Maletz K, Bruhl H, Schlondorff D: Chondroitin sulfate a released from platelets blocks RANTES presentation on cell surfaces and RANTESdependent firm adhesion of leukocytes. Eur J Immunol 2002;32:1012-1020.

75 Gudbrandsdottir S, Hasselbalch HC, Nielsen CH: Activated platelets enhance IL-10 secretion and reduce TNF-alpha secretion by monocytes. J Immunol 2013; 191:4059-4067.

76 Ando Y, Oku T, Tsuji T: Platelets attenuate production of cytokines and nitric oxide by macrophages in response to bacterial endotoxin. Platelets 2015:1-7.

77 Inui M, Tazawa K, Kishi Y, Takai T: Platelets convert peripheral blood circulating monocytes to regulatory cells via immunoglobulin $\mathrm{g}$ and activating-type $\mathrm{FC} \gamma$ receptors. BMC Immunol 2015;16:20.

78 Corken A, Russell S, Dent J, Post SR, Ware J: Platelet glycoprotein Ib-IX as a regulator of systemic inflammation. Arterioscler Thromb Vasc Biol 2014;34:9961001.

79 Brancaleone V, Gobbetti T, Cenac N, le Faouder P, Colom B, Flower RJ, Vergnolle N, Nourshargh S, Perretti M: A vasculo-protective circuit centered on lipoxin a 4 and aspirin-triggered 15 -epi-lipoxin a 4 operative in murine microcirculation. Blood 2013;122: 608-617.
0 Brunetti M, Martelli N, Manarini S, Mascetra N, Musiani P, Cerletti C, Aiello FB, Evangelista V: Polymorphonuclear leukocyte apoptosis is inhibited by platelet-released mediators, role of TGFbeta-1. Thromb Haemost 2000;84:478-483

81 Ariel A, Fredman G, Sun YP, Kantarci A, Van Dyke TE, Luster AD, Serhan CN: Apoptotic neutrophils and $\mathrm{T}$ cells sequester chemokines during immune response resolution through modulation of CCR5 expression. Nat Immunol 2006;7:1209-1216.

82 Hilf N, Singh-Jasuja H, Schwarzmaier P, Gouttefangeas C, Rammensee HG, Schild H: Human platelets express heat shock protein receptors and regulate dendritic cell maturation. Blood 2002;99:3676-3682.

83 Huo Y, Schober A, Forlow SB, Smith DF, Hyman MC, Jung S, Littman DR, Weber C, Ley K: Circulating activated platelets exacerbate atherosclerosis in mice deficient in apolipoprotein e. Nat Med 2003;9:61-67.

84 Karshovska E, Zhao Z, Blanchet X, Schmitt MM, Bidzhekov K, Soehnlein O, von Hundelshausen P, Mattheij NJ, Cosemans JM, Megens RT, Koeppel TA, Schober A, Hackeng TM, Weber C, Koenen RR: Hyperreactivity of junctional adhesion molecule A-deficient platelets accelerates atherosclerosis in hyperlipidemic mice. Circ Res 2015;116:587-599.

85 Jickling GC, Liu D, Ander BP, Stamova B, Zhan X, Sharp FR: Targeting neutrophils in ischemic stroke: translational insights from experimental studies. J Cereb Blood Flow Metab 2015;35:888-901.

86 von Hundelshausen P, Schmitt MM: Platelets and their chemokines in atherosclerosis - clinical applications. Front Physiol 2014;5:294.

87 Badrnya S, Butler LM, Soderberg-Naucler C, Volf I, Assinger A: Platelets directly enhance neutrophil transmigration in response to oxidised low-density lipoprotein. Thromb Haemost 2012;108:719-729.

88 Langer HF, Daub K, Braun G, Schonberger T, May AE, Schaller M, Stein GM, Stellos K, Bueltmann A, SiegelAxel D, Wendel HP, Aebert H, Roecken M, Seizer P, Santoso S, Wesselborg S, Brossart P, Gawaz M: Platelets recruit human dendritic cells via MAC-1/JAM-C interaction and modulate dendritic cell function in vitro. Arterioscler Thromb Vasc Biol 2007;27:1463-1470.

89 Lievens D, Zernecke A, Seijkens T, Soehnlein O, Beckers L, Munnix IC, Wijnands E, Goossens P, van Kruchten R, Thevissen L, Boon L, Flavell RA, Noelle RJ, Gerdes N, Biessen EA, Daemen MJ, Heemskerk JW, Weber C, Lutgens E: Platelet CD40L mediates thrombotic and inflammatory processes in atherosclerosis. Blood 2010;116:4317-4327.

90 Scheuerer B, Ernst M, Durrbaum-Landmann I, Fleischer J, Grage-Griebenow E, Brandt E, Flad HD, Petersen F: The CXC-chemokine platelet factor 4 promotes monocyte survival and induces monocyte differentiation into macrophages. Blood 2000;95:1158-1166.

91 Gleissner CA: Macrophage phenotype modulation by cxcl4 in atherosclerosis. Front Physiol 2012;3:1.

92 Mendelsohn ME, Loscalzo J: Role of platelets in cholesteryl ester formation by U-937 cells. J Clin Invest 1988;81:62-68.

93 Daub K, Langer H, Seizer P, Stellos K, May AE, Goyal P, Bigalke B, Schonberger T, Geisler T, Siegel-Axel D, Oostendorp RA, Lindemann S, Gawaz M: Platelets induce differentiation of human CD34+ progenitor cells into foam cells and endothelial cells. FASEBJ 2006;20: 2559-2561.

94 De Meyer GR, De Cleen DM, Cooper S, Knaapen MW Jans DM, Martinet W, Herman AG, Bult H, Kockx MM: Platelet phagocytosis and processing of beta-amyloid precursor protein as a mechanism of macrophage activation in atherosclerosis. Circ Res 2002;90:1197-1204. 
-95 Nassar T, Sachais BS, Akkawi S, Kowalska MA, Bdeir K, Leitersdorf E, Hiss E, Ziporen L, Aviram M, Cines D, Poncz M, Higazi AA: Platelet factor 4 enhances the binding of oxidized low-density lipoprotein to vascular wall cells. J Biol Chem 2003;278:6187-6193.

96 Fuhrman B, Brook GJ, Aviram M: Proteins derived from platelet alpha granules modulate the uptake of oxidized low density lipoprotein by macrophages. Biochim Biophys Acta 1992;1127:15-21.

97 Sachais BS, Turrentine T, Dawicki McKenna JM, Rux AH, Rader D, Kowalska MA: Elimination of platelet factor 4 (PF4) from platelets reduces atherosclerosis in C57Bl/6 and apoE-/- mice. Thromb Haemost 2007;98: 1108-1113.

98 Ikuta T, Naruko T, Ikura Y, Ohsawa M, Fukushima H, Shirai N, Itoh A, Haze K, Ehara S, Sasaki Y, Shibata T, Suehiro S, Ueda M: Immunolocalization of platelet glycoprotein IIb/IIIa and P-selectin, and neutrophilplatelet interaction in human coronary unstable plaques. Int J Mol Med 2005; 15:573-577.

99 Haseruck N, Erl W, Pandey D, Tigyi G, Ohlmann P, Ravanat C, Gachet C, Siess W: The plaque lipid lysophosphatidic acid stimulates platelet activation and platelet-monocyte aggregate formation in whole blood: Involvement of P2Y1 and P2Y12 receptors. Blood 2004;103:2585-2592.

100 Schmidt R, Bultmann A, Fischel S, Gillitzer A, Cullen P, Walch A, Jost P, Ungerer M, Tolley ND, Lindemann S, Gawaz M, Schomig A, May AE: Extracellular matrix metalloproteinase inducer (CD147) is a novel receptor on platelets, activates platelets, and augments nuclear factor kappaB-dependent inflammation in monocytes. Circ Res 2008;102:302-309.

101 Galt SW, Lindemann S, Medd D, Allen LL, Kraiss LW, Harris ES, Prescott SM, McIntyre TM, Weyrich AS, Zimmerman GA: Differential regulation of matrix metalloproteinase- 9 by monocytes adherent to collagen and platelets. Circ Res 2001;89:509-516.
102 Niessner A, Weyand CM: Dendritic cells in atherosclerotic disease. Clin Immunol 2010;134:25-32.

103 Manfredi AA, Rovere-Querini P, Maugeri N: Dangerous connections: neutrophils and the phagocytic clearance of activated platelets. Curr Opin Hematol 2010; 17:3-8.

104 Maitre B, Mangin PH, Eckly A, Heim V, Cazenave JP, Lanza F, Hanau D, Gachet C: Immature myeloid dendritic cells capture and remove activated platelets from preformed aggregates. J Thromb Haemost 2010;8: 2262-2272.

105 Trinh BQ, Barengo N, Kim SB, Lee JS, ZweidlerMcKay PA, Naora H: The homeobox gene DLX4 regulates erythro-megakaryocytic differentiation by stimulating IL-1beta and NF- $\mathrm{KB}$ signaling. J Cell Sci 2015; 128:3055-3067.

106 Wickenhauser C, Lorenzen J, Thiele J, Hillienhof A, Jungheim K, Schmitz B, Hansmann ML, Fischer R: Secretion of cytokines (interleukins-1 alpha, -3 , and - 6 and granulocyte-macrophage colony-stimulating factor) by normal human bone marrow megakaryocytes. Blood 1995;85:685-691.

107 Jiang S, Levine JD, Fu Y, Deng B, London R, Groopman JE, Avraham H: Cytokine production by primary bone marrow megakaryocytes. Blood 1994;84:41514156 .

108 Zheng C, Yang R, Han Z, Zhou B, Liang L, Lu M: TPO-independent megakaryocytopoiesis. Crit Rev Oncol Hematol 2008;65:212-222.

109 Angchaisuksiri P, Grigus SR, Carlson PL, Krystal GW, Dessypris EN: Secretion of a unique peptide from interleukin-2-stimulated natural killer cells that induces endomitosis in immature human megakaryocytes. Blood 2002;99:130-136.

110 Machlus KR, Thon JN, Italiano JE Jr: Interpreting the developmental dance of the megakaryocyte: a review of the cellular and molecular processes mediating platelet formation. Br J Haematol 2014;165:227-236.
111 Ricciardi S, Miluzio A, Brina D, Clarke K, Bonomo M, Aiolfi R, Guidotti LG, Falciani F, Biffo S: Eukaryotic translation initiation factor 6 is a novel regulator of reactive oxygen species-dependent megakaryocyte maturation. J Thromb Haemost 2015;13:2108-2118.

112 Wu D, Xie J, Wang X, Zou B, Yu Y, Jing T, Zhang S, Zhang Q: Micro-concentration lipopolysaccharide as a novel stimulator of megakaryocytopoiesis that synergizes with IL-6 for platelet production. Sci Rep 2015;5: 13748.

113 Nishimura S, Nagasaki M, Kunishima S, Sawaguchi A, Sakata A, Sakaguchi H, Ohmori T, Manabe I, Italiano JE, Jr., Ryu T, Takayama N, Komuro I, Kadowaki T, Eto K, Nagai R: IL-1alpha induces thrombopoiesis through megakaryocyte rupture in response to acute platelet needs. J Cell Biol 2015;209:453-466.

114 Kohler A, De Filippo K, Hasenberg M, van den Brand C, Nye E, Hosking MP, Lane TE, Mann L, Ransohoff RM, Hauser AE, Winter O, Schraven B, Geiger H, Hogg N, Gunzer M: G-CSF-mediated thrombopoietin release triggers neutrophil motility and mobilization from bone marrow via induction of CXCR2 ligands. Blood 2011;117:4349-4357.

115 Frisch J, Ganser A, Hoelzer D, Brugger W, Kanz L, Mertelsmann R, Schulz G: Interleukin-3 and granulocyte-macrophage colony-stimulating factor in combination: Clinical implication. Med Pediatr Oncol Suppl 1992;2:34-37.

116 van Gameren MM, Willemse PH, Mulder NH, Limburg PC, Groen HJ, Vellenga E, de Vries EG: Effects of recombinant human interleukin-6 in cancer patients: a phase I-II study. Blood 1994;84:1434-1441. 